\title{
Non-invasive tracing of liver intermediary metabolism in normal subjects and in moderately hyperglycaemic NIDDM subjects. Evidence against increased gluconeogenesis and hepatic fatty acid oxidation in NIDDM
}

\author{
F. Diraison ${ }^{1}$, V. Large ${ }^{1}$, H. Brunengraber ${ }^{2}$, M. Beylot ${ }^{1,3}$ \\ ${ }^{1}$ Laboratoire de Physiopathologie Métabolique et Rénale, Faculté de Médecine R. Laennec, Lyon, France \\ ${ }^{2}$ Department of Nutrition, Case Western Reserve University, Cleveland, Ohio, USA \\ ${ }^{3}$ Centre de Recherche en Nutrition Humaine Hopital Edouard Herriot, Lyon, France
}

\begin{abstract}
Summary To test whether gluconeogenesis is increased in non-insulin-dependent diabetic (NIDDM) patients we infused (post-absorptive state) healthy subjects and NIDDM patients with $\left[6,6-{ }^{2} \mathrm{H}_{2}\right]$ glucose $(150 \mathrm{~min})$ and $\left[3-{ }^{13} \mathrm{C}\right]$ lactate $(6 \mathrm{~h})$. Liver glutamine was sampled with phenylacetate and its labelling pattern determined (mass spectrometry) after purification of the glutamine moiety of urinary phenylacetylglutamine. After correction for ${ }^{13} \mathrm{CO}_{2}$ re-incorporation (control test with $\mathrm{NaH}^{13} \mathrm{CO}_{3}$ infusion) this pattern was used to calculate the dilution factor $(F)$ in the hepatic oxaloacetate pool and fluxes through liver Krebs cycle. NIDDM patients had increased lactate turnover rates $(16.18 \pm 0.92$ vs $12.14 \pm$ $\left.0.60 \mu \mathrm{mol} \cdot \mathrm{kg}^{-1} \cdot \mathrm{min}^{-1}, p<0.01\right)$ and a moderate rise in glucose production (EGP) $(15.39 \pm 0.87$ vs $12.52 \pm$ $\left.0.28 \mu \mathrm{mol} \cdot \mathrm{kg}^{-1} \cdot \mathrm{min}^{-1}, p=0.047\right)$. Uncorrected contributions of gluconeogenesis to EGP were $31 \pm 3 \%$ (control subjects) and $17 \pm 2 \%$ (NIDDM patients).
\end{abstract}

F was comparable $(1.34 \pm 0.02$ and $1.39 \pm 0.09$, respectively) and the corrected percent and absolute contributions of gluconeogenesis were not increased in NIDDM $\left(25 \pm 3 \%\right.$ and $3.8 \pm 0.5 \mu \mathrm{mol} \cdot \mathrm{kg}^{-1}$. $\left.\min ^{-1}\right)$ compared to control subjects $(41 \pm 3 \%$ and $\left.5.1 \pm 0.4 \mu \mathrm{mol} \cdot \mathrm{kg}^{-1} \cdot \mathrm{min}^{-1}\right)$. The calculated pyruvate carboxylase over pyruvate dehydrogenase activity ratio was comparable $(12.1 \pm 2.6$ vs $11.2 \pm 1.4)$. Lastly hepatic fatty oxidation, as estimated by the model, was not increased in NIDDM $(1.8 \pm 0.4$ vs $1.6 \pm$ $\left.0.1 \mu \mathrm{mol} \cdot \mathrm{kg}^{-1} \cdot \mathrm{min}^{-1}\right)$. In conclusion, in the patients studied we found no evidence of increased hepatic fatty oxidation, or, despite the increased lactate turnover rate, an increased gluconeogenesis. [Diabetologia (1998) 41: 212-220]

Keywords Krebs cycle, stable isotope, mass spectrometry, gluconeogenesis, fatty acid oxidation.
The hyperglycaemia of post-absorptive non-insulindependent diabetic (NIDDM) subjects is considered to result from impaired glucose utilization and increased endogenous glucose production (EGP) [1].

Received: 4 July 1997 and in revised form: 16 September 1997

Corresponding author: M. Beylot M.D., Ph. D., Laboratoire de Physiopathologie Métabolique et Rénale, Faculté de Médecine R. Laennec, Rue G. Paradin, F-69008 Lyon, France Abbreviations: NIDDM, Non-insulin-dependent diabetes mellitus; EGP, endogenous glucose production; PAGN, phenylacetylglutamine; IE, isotopic enrichment; MPE, mole per cent excess; Rt, turnover rate; PK, pyruvate kinase; PC, pyruvate carboxylase; PEPCK, phosphoenolpyruvate carboxykinase; PDH, pyruvate dehydrogenase; CS, citrate synthesis; NEFA, non-esterified fatty acids.
This elevated EGP has been attributed to an accelerated gluconeogenesis [2] itself explained by enhanced delivery of gluconeogenic substrates to the liver and increased efficiency of intra-hepatic substrate conversion to glucose [3]. However, the role of an increased EGP has been challenged since, when appropriate priming of the glucose pool by the tracer infused is performed, high EGP values are found only in markedly hyperglycaemic subjects [4-6]. In patients with mild or moderate hyperglycaemia EGP is only slightly elevated or within the normal range, although it can be considered as inappropriately high in the presence of hyperglycaemia. The finding of an accelerated gluconeogenesis was mainly based on studies using labelled acetate, a method recognized as non-valid for in vivo studies of gluconeogenesis [7-9]. More- 
over the percent contribution of gluconeogenesis to EGP in NIDDM subjects was found to be normal in a study [10] using [U $\left.-{ }^{13} \mathrm{C}\right]$ glucose infusion and the mass isotopomer distribution of plasma glucose to calculate this contribution.

In vivo quantitative measurements of gluconeogenesis are hampered by two main problems: isotopic exchanges in the hepatic oxaloacetate pool [11] and dilution of the gluconeogenic precursor enrichment between peripheral plasma and liver [12]. One approach to solve these problems is the non-invasive chemical biopsy of liver glutamine developed by Magnusson and Landau [13,14]. These authors used the labelling pattern of hepatic glutamine during the infusion of $\left[3-{ }^{14} \mathrm{C}\right]$ lactate to trace Krebs cycle activity and gluconeogenesis in normal subjects [13] and insulin-dependent diabetic patients [14]. Liver glutamine was non-invasively sampled by its conjugation with phenylacetate forming phenylacetylglutamine (PAGN) which is excreted in urine [15]. The glutamine labelling pattern was used to calculate rates of Krebs cycle activity, expressed relative to citrate synthesis, and the isotopic dilution at the oxaloacetate crossroads using equations developed by Magnusson et al. [13]. We showed that this method detects modifications of flux through key enzymes of liver intermediary metabolism, such as pyruvate kinase (PK), pyruvate dehydrogenase (PDH), phosphoenolpyruvate carboxykinase (PEP$\mathrm{CK})$ and pyruvate carboxylase (PC), and allows calculation of accurate dilutions between liver pyruvate and phosphoenolpyruvate [16]. Moreover, L- $\left[3-{ }^{14} \mathrm{C}\right]$ lactate or $\mathrm{L}-\left[3-{ }^{13} \mathrm{C}\right]$ lactate appear appropriate for in vivo investigations of liver intermediary metabolism, provided that correction for re-incorporation of labelled $\mathrm{CO}_{2}$ by exchange processes, is performed $[9,13,17]$.

In the present study we used this approach to calculate relative rates of Krebs cycle activity and gluconeogenesis, as well as the intra-hepatic dilution factor (between pyruvate and phosphoenolpyruvate), in post-absortive normal and NIDDM subjects. In addition we propose solving the problem of dilution of the enrichment of the gluconeogenic precursor between peripheral blood and liver by measuring alanine enrichment in plasma [18]. Finally, since total glucose production was also measured, we calculated absolute rates of gluconeogenesis and therefore absolute fluxes through hepatic metabolic pathways such as citrate synthesis (CS), pyruvate carboxylation and dehydrogenation for fatty acid oxidation.

\section{Subjects, materials and methods}

Materials. Tracers were from Eurisotop (Saint Aubin, France) $\left(\left[6,6-{ }^{2} \mathrm{H}_{2}\right]\right.$ glucose, $\mathrm{NaH}^{13} \mathrm{CO}_{3}$ ) or Mass trace (Woburn, Mass., USA) $\left(\mathrm{L}-\left[3-{ }^{13} \mathrm{C}\right]\right.$ lactate). Reagents and enzymes were from
Sigma (St. Louis, Mo., USA) or Boehringer (Mannheim, Germany).

Subjects. After approval by the local ethical commitee and the INSERM informed written consent was obtained from five healthy volunteers (three men, two women, aged 24 to 46 years, body weight $64 \pm 2 \mathrm{~kg}$, body mass index $21-25 \mathrm{~kg}$ / $\mathrm{m}^{2}$ ) and five NIDDM patients (four men, one woman, aged 34 to 53 years, body weight $83 \pm 6 \mathrm{~kg}$, body mass index $27-$ $32 \mathrm{~kg} / \mathrm{m}^{2}$ ). The duration of diabetes was 4 to 8 years; $\mathrm{HbA}_{1 \mathrm{c}}$ levels were 9.5 to $11.0 \%$ (normal values $<6.0 \%$ ). No control subject had a personal or familial history of diabetes or obesity or was taking any medication. All consumed a weight maintaining diet containing at least $200 \mathrm{~g}$ carbohydrate and had abstained from alcohol or heavy physical activity during the week before the studies. The diabetic patients were treated by diet alone (three subjects) or diet and metformin (two subjects). This medication was interrupted 3 days before the studies and the diabetic subjects consumed a weight maintaining diet during this period. The last meal was ingested between 19.00 and 20.00 hours the day before the tests.

Protocols. All tests were performed in the Centre de Recherche de Nutrition Humaine, Lyon. The subjects were studied twice, once with infusions of L- $\left[3-{ }^{13} \mathrm{C}\right]$ lactate and D- $\left[6,6{ }^{2} \mathrm{H}_{2}\right]$ glucose (test 1) and once with an infusion of $\mathrm{NaH}^{13} \mathrm{CO}_{3}$ (test 2), with at least 1 week between the tests. All tests were initiated with the patients in the post-absorptive state, after an overnight fast. At 07.30 hours indwelling catheters were placed in a forearm vein for tracer infusion and in a dorsal vein of the opposite hand kept at $55^{\circ} \mathrm{C}$ to collect arterialized blood. During test 1 , after initial blood sampling, primed-continuous infusion of $\mathrm{D}-\left[6,6-{ }^{2} \mathrm{H}_{2}\right]$ glucose $(3 \mathrm{mg} / \mathrm{kg}, \quad 0.02-$ $0.03 \mathrm{mg} \cdot \mathrm{kg}^{-1} \cdot \mathrm{min}^{-1}$ during $\left.150 \mathrm{~min}\right)$ and $\mathrm{L}-\left[3-{ }^{13} \mathrm{C}\right]$ lactate $\left(10 \mu \mathrm{mol} / \mathrm{kg}, \quad 0.60-0.77 \mu \mathrm{mol} \cdot \mathrm{kg}^{-1} \cdot \mathrm{min}^{-1}\right.$ during $\left.360 \mathrm{~min}\right)$ were initiated. Blood was collected at 60, 120, 130, 140, 150, 240, 300, 320, 340, and $360 \mathrm{~min}$. The subjects consumed Aspartam (N-L- $\alpha$-aspartyl-L-phenylalanine-1-methyl ester; Searle, Boulogne, France) $(1 \mathrm{mg} / \mathrm{kg})$ at $60 \mathrm{~min}$. Urine was collected at the end of the test. During test $2, \mathrm{NaH}^{13} \mathrm{CO}_{3}(0.75 \mu \mathrm{mol}$. $\mathrm{kg}^{-1} \cdot \mathrm{min}^{-1}$ ) was infused for $360 \mathrm{~min}$. Blood was sampled before tracer infusion and at 240, 300, 320, 340, and $360 \mathrm{~min}$ and samples of expired gas were also collected before tracer infusion and at the time of blood sampling. The subjects also consumed Aspartam and urine was collected at the end of the test.

Analytical procedures. Metabolites were assayed by enzymatic methods [19] on neutralized perchloric acid extracts of plasma or plasma (NEFA) and plasma insulin [20] and glucagon [21] by radioimmunoassay. The isotopic enrichments (IE, expressed as mole per cent excess, MPE) of plasma lactate $(\mathrm{m} /$ z 261) and pyruvate ( $\mathrm{m} / \mathrm{z} 217)$ were measured as previously described [12]. Plasma alanine was purified by cation exchange chromatography (AG50 WX4 H + form; Biorad, Richmond, Calif., USA) and the IE measured using the t-butyldimethylsilyl derivative ( $\mathrm{m} / \mathrm{z} 260)$ [16]. Plasma urea was purified by sequential anion-cation exchange chromatography and the IE determined as described [22]. Plasma glucose was purified by ion-exchange chromatography. For test 2 , the IE was determined by gas chromatography-isotope ratio mass spectrometry [23] (Sira12, Vg Isogas; Middlewitch, UK). For test 1, deuterium enrichment during the 120-150 min period was determined using either the ions of $\mathrm{m} / \mathrm{z} 217\left(\mathrm{~m}_{0}\right)$ and 219 $\left(\mathrm{m}_{+2}\right)$ (containing carbons 4 to 6 of glucose) of the aldonitrile pentaacetate derivative or the ions 117 and 119, and 205 and 207, (carbons 5-6) of the methyloxime trimethylsilyl derivative [24]. ${ }^{13} \mathrm{C}$ incorporation from the infused labelled lactate 
resulted in an increase of the ions $\mathrm{m}_{+1}(218,118,206)$; corrections for the additional increases in $\mathrm{m}_{+2}$ induced by this incorporation of ${ }^{13} \mathrm{C}$ into glucose were performed using appropriate standard curves [25]. Total ${ }^{13} \mathrm{C}$ enrichment of glucose at the end of the test (300-360 min) was measured using the bisbutylboronate-acetate or the pentaacetate derivative of glucose [24]. The individual ${ }^{13} \mathrm{C}$ labelling of the six carbon atoms of glucose was determined as previously described [24]. Methods for the hydrolysis of PAGN and analysis of the labelling pattern of its glutamine moiety have been published previously $[17,26,27]$. Since we infused glucose deuterated on carbon 6 we considered the possibility that deuterium could label the glutamine moeity of PAGN, particularly on C-4, and modify its labelling pattern since the mass spectrometric method used does not differentiate deuterium and ${ }^{13} \mathrm{C}$ labelling. To test for this possibility we infused, in a control experiment, post-absorptive rats with $\left[6,6-{ }^{2} \mathrm{H}_{2}\right]$ glucose in order to obtain glucose enrichment (2-3\%) much higher than the IE obtained in human subjects $(0.7-1 \%)$ and liver glutamate was purified; no significant deuterium labelling was detected. ${ }^{13} \mathrm{C}$ enrichment of $\mathrm{CO}_{2}$ in expired gas was measured by gas-chromatography isotope ratio mass spectrometry [28]. All gas chromatography mass spectrometry analysis was performed with a gas chromatograph (HP5890; Hewlett-Packard, Palo Alto, Calif., USA) equipped with a $25 \mathrm{~m}$ fused silica capillary column (OV1701; Chrompack, Bridgewater, N.J., USA) and interfaced with a HP5971A mass spectrometer (Hewlett-Packard). Carrier gas was helium. Standard curves prepared by mixing weighted amounts of natural and ${ }^{2} \mathrm{H}$ or ${ }^{13} \mathrm{C}$ labelled lactate, pyruvate, alanine, urea, glucose and glutamate were run before and after the corresponding biological samples (all in triplicate). Special care was taken to have comparable peak areas (i.e., $<20 \%$ difference) between the standard and biological samples.

Calculations. Glucose turnover rates $(\mathrm{Rt})$ were calculated from its deuterium enrichment during the 120-150 min period using steady-state equations. Measurement of IE at $60 \mathrm{~min}$ allowed us to verify that plateau enrichment was already obtained and that the priming dose was correctly adapted in all subjects. Lactate Rt was also calculated by steady-state equations using ${ }^{13} \mathrm{C}$ enrichment measured during the 300-360 min period; this was performed using either lactate or pyruvate IE [12]. The labelling patterns of glutamate isolated from PAGN during test 1 were corrected for the re-incorporation of labelled carbon in position 1 through the fixation of ${ }^{13} \mathrm{CO}_{2}$ using the IE of urea measured during tests 1 and 2, and the labelling of carbon 1 of the glutamate of PAGN during the test with $\mathrm{NaH}^{13} \mathrm{CO}_{3}$ infusion, as described by Magnusson et al. [13]. These corrected labelling patterns were used to calculate Krebs cycle parameters and the dilution factor at the oxaloacetate crossroad (F) using the model (Fig.1) and equations of Magnusson et al. [13]. The equations yield rates expressed relative to citrate synthesis (CS), or Krebs cycle activity (V3 in the model). Gluconeogenesis was first calculated from the ratio of half glucose IE to either plasma lactate, pyruvate or alanine IE. These contributions, calculated as percentages, of gluconeogenesis to EGP (gng\%) were corrected by $\mathrm{F}$, and the corresponding absolute gluconeogenic rates were calculated as gng $=\mathrm{gng} \% \cdot \mathrm{F} \cdot$ glucose Rt. Two times this rate corresponds to the rate V9 (phosphoenolpyruvate to glucose) in Magnussons's model. It was then possible to convert all the relative fluxes previously calculated into absolute values. Since glucose labelling patterns were also determined the correction factors for isotopic exchange in the oxaloacetate pool were also calculated [29] with the equation derived from the Katz model [30] $\mathrm{f}=[2(1+2 \mathrm{y})(1+\mathrm{y})] /$ $[(5+4 y) y]$ where y (ratio of PC over CS activity) is obtained

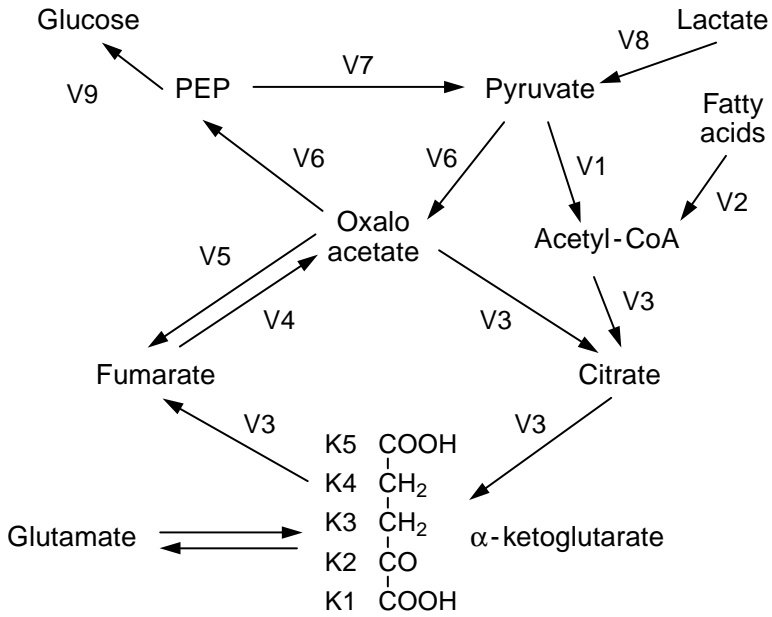

Fig.1. Model of Krebs'cycle and gluconeogenesis
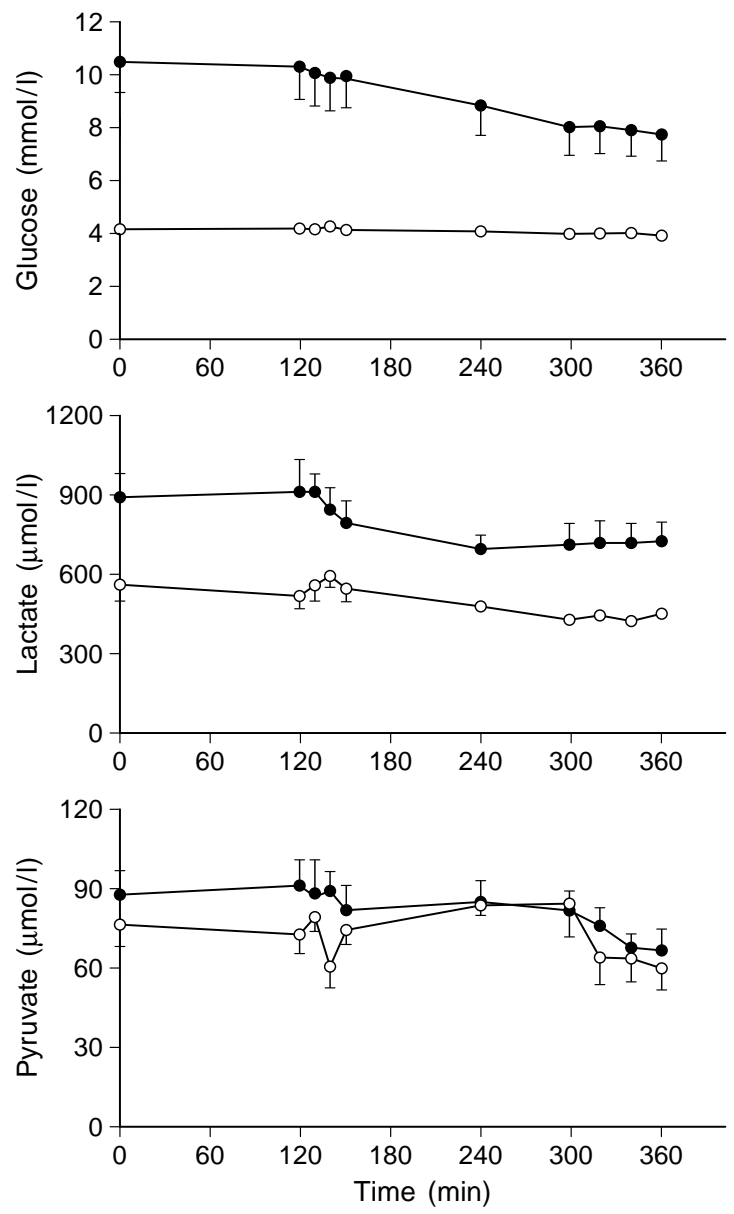

Fig. 2. Concentrations of glucose, lactate and pyruvate during the $6 \mathrm{~h}$ of the protocol in control $(O)$ and diabetic $(\bullet)$ subjects

from the ratio $\mathrm{R}$ of the average enrichment of plasma glucose carbons 1,2, 5 and 6 over the average enrichment of carbons 3 and 4 as: $\mathrm{y}=(\mathrm{R}-2) / 2$. This model [30] assumes that $\mathrm{PDH}$ activity in liver is negligible. If PDH activity is not negligible the equation is $\mathrm{f}=[2(1+2 \mathrm{y})(1+\mathrm{y})] /[(5+4 \mathrm{y})(\mathrm{y}+\mathrm{x})]$ where $\mathrm{x}$ is the ratio of $\mathrm{PDH}$ over CS activity. Since this ratio was obtained from the labelling pattern of PAGN, we made the calculations 
Table 1. Glycerol, NEFA and D- $\beta$-hydroxybutyrate (D- $\beta$-OHB) levels

\begin{tabular}{|c|c|c|c|c|c|c|}
\hline \multirow[t]{2}{*}{ Time (min) } & \multicolumn{3}{|c|}{ Control subjects } & \multicolumn{3}{|c|}{ Diabetic patients } \\
\hline & 120 & 240 & 360 & 120 & 240 & 360 \\
\hline Glycerol $(\mu \mathrm{mol} / \mathrm{l})$ & $92 \pm 17$ & $124 \pm 21$ & $144 \pm 7$ & $117 \pm 22$ & $121 \pm 20$ & $117 \pm 30$ \\
\hline $\mathrm{D}-\beta$-OHB $(\mu \mathrm{mol} / \mathrm{l})$ & $104 \pm 36$ & $232 \pm 80$ & $593 \pm 301^{b}$ & $38 \pm 7^{\mathrm{d}}$ & $58 \pm 25^{\mathrm{c}}$ & $86 \pm 42^{\mathrm{a}, \mathrm{d}}$ \\
\hline
\end{tabular}

Results are shown as mean \pm SEM. ${ }^{\mathrm{a}} p<0.05,{ }^{\mathrm{b}} p<0.01$ vs time 120 min of the same group; ${ }^{\mathrm{c}} p<0.05$, ${ }^{\mathrm{d}} p<0.01$ vs the corresponding time of the other group

Table 2. Hormonal parameters and glucose and lactate turnover rates

\begin{tabular}{lcc}
\hline & Control subjects & Diabetic patients \\
\hline Insulin $(\mathrm{mU} / \mathrm{l})$ & $7.6 \pm 0.9$ & $17.1 \pm 2.6^{\mathrm{a}}$ \\
Glucagon $(\mathrm{ng} / \mathrm{l})$ & $118 \pm 14$ & $109 \pm 18$ \\
$\begin{array}{l}\text { Glucose Rt } \\
\left(\mu \mathrm{mol} / \mathrm{kg} \cdot \mathrm{min}^{-1}\right)\end{array}$ & $12.52 \pm 0.28$ & $15.39 \pm 0.87^{\mathrm{a}}$ \\
$\mathrm{Lactate} \mathrm{Rt}$ & & \\
$\left(\mu \mathrm{mol} / \mathrm{kg} \cdot \mathrm{min}^{-1}\right)$ & $10.01 \pm 0.67$ & $14.80 \pm 0.78^{\mathrm{a}}$ \\
& $12.14 \pm 0.60$ & $16.18 \pm 0.92^{\mathrm{a}}$ \\
\hline
\end{tabular}

Results are shown as mean \pm SEM. ${ }^{a} p<0.05$ vs controls. Lactate Rt was calculated using lactate (upper line) or pyruvate (lower line) IE

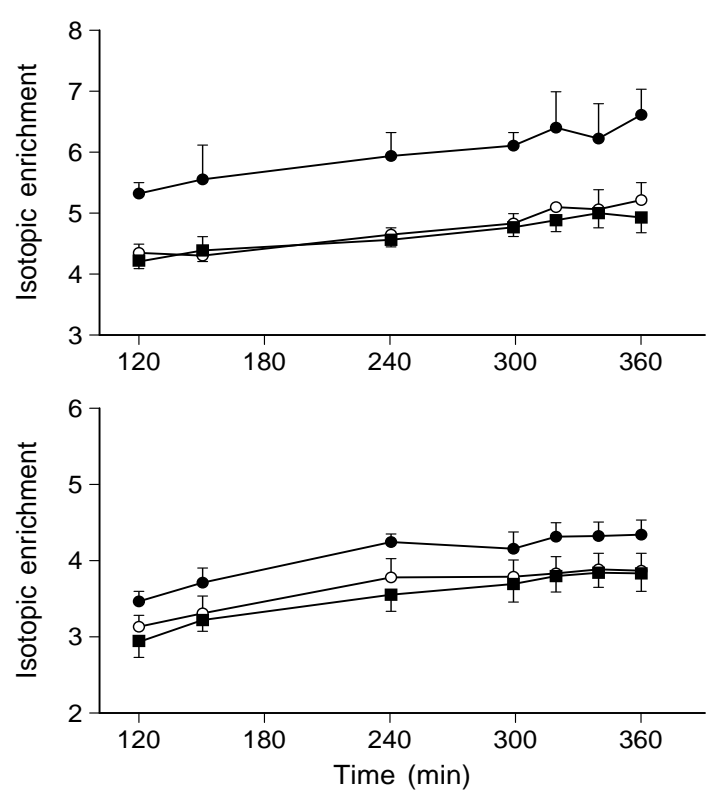

Fig.3. Isotopic enrichments (MPE) of lactate (•), pyruvate $(\mathrm{O})$ and alanine ( $\boldsymbol{\square})$ in control (upper panel) and diabetic (lower panel) subjects

with the two formulas. These calculations were performed after correcting the IE of carbons 3 and 4 of glucose for the re-incorporation of labelled $\mathrm{CO}_{2}$ by $\mathrm{PC}$ as described by Magnusson et al. [13]. The percent of plasma lactate incorporated into glucose was calculated as the flux of ${ }^{13} \mathrm{C}$-labelled glucose (glucose $\mathrm{Rt} * \mathrm{IE}$ ) divided by ${ }^{13} \mathrm{C}$ lactate infusion rate (i.e. the ratio of the ${ }^{13} \mathrm{C}$ flux in glucose over the infused flux of $\left.{ }^{13} \mathrm{C}\right)$. This was performed with and without correction for isotopic dilution in the oxaloacetate pool.
Statistical analysis. Unless stated otherwise, data are expressed as mean \pm SEM. Between group comparisons were made by Student's $t$-test for non-paired data and within group comparison by Student's $t$-test for paired data.

\section{Results}

Hormonal and metabolique concentrations. The evolution of lactate, pyruvate and glucose concentrations during test 1 are shown in Figure 2. In normal subjects there was no significant variation. Glucose, lactate and pyruvate decreased progressively in diabetic patients but were higher than in control subjects throughout the tests. There were no significant differences in NEFA and glycerol levels between the two groups (Table 1 ). D- $\beta$-hydroxybutyrate increased only slightly in diabetic patients $(p<0.05)$; this increase was more important $(p<0.01)$ in normal subjects. Moreover $\mathrm{D}-\beta$-hydroxybutyrate was higher in normal than in diabetic subjects $(p<0.05)$. Comparable evolutions were observed during test 2 (data not shown). Diabetic patients had increased insulinaemia but no modifications of glugacon levels (Table 2).

Glucose and lactate turnover rates (Table 2). Glucose Rt were only slightly increased in diabetic patients $(p=0.047)$ when expressed relative to body weight but were largely (1.6 times) higher when expressed in $\mu \mathrm{mol} / \mathrm{min}(1296 \pm 82$ vs $797 \pm 37, p<0.01)$. Lactate, pyruvate and plasma alanine IE are shown in Figure 3. Lactate Rt were calculated using either lactate or pyruvate IE. In both diabetic and control subjects pyruvate IE was lower than lactate and therefore the apparent lactate $\mathrm{Rt}$ was higher when pyruvate IE was used for the calculation. Whatever the enrichment chosen, lactate Rt was increased in diabetic patients $(p<0.05$, Table 2$)$. Apparent gluconeogenic rates were calculated from the ${ }^{13} \mathrm{C}$ enrichment of glucose (Fig. 4) and the enrichment of either plasma lactate, pyruvate or alanine (Table 3 ); whatever precursor was used, the uncorrected fractional gluconeogenic rate was lower in diabetic patients $(p<0.05)$.

Parameters of Krebs cycle activity and intra-hepatic dilution factor. The corrected labelling patterns of the glutamine moiety of urinary PAGN are shown in 


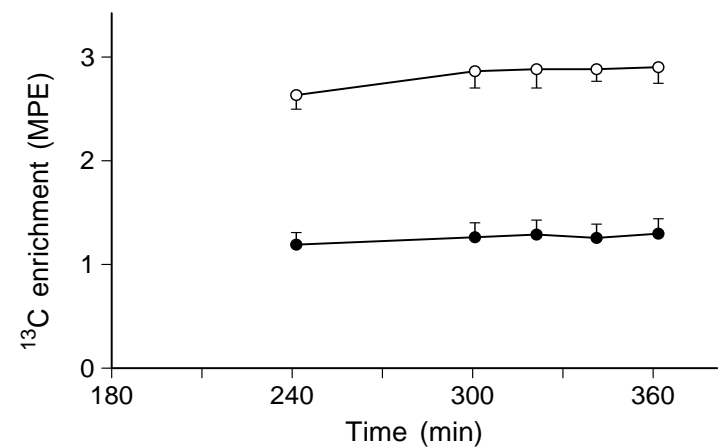

Fig.4. Total ${ }^{13} \mathrm{C}$ enrichment (MPE) of glucose in control $(\mathrm{O})$ and diabetic $(\bullet)$ subjects

Table 3. Estimate of lactate utilization for gluconeogenesis and of the contribution of gluconeogenesis to EGP

\begin{tabular}{|c|c|c|}
\hline & Control subjects & Diabetic patients \\
\hline $\begin{array}{l}\text { Lactate utilization fo } \\
\text { uncorrected } \\
\text { corrected }\end{array}$ & $\begin{array}{l}\text { neogenesis (\%) } \\
59.4 \pm 2.4 \\
79.6 \pm 2.8\end{array}$ & $\begin{array}{l}29.9 \pm 2.2^{\mathrm{b}} \\
43.8 \pm 4.3^{\mathrm{b}}\end{array}$ \\
\hline $\begin{array}{l}\text { Gluconeogenesis (\% } \\
\text { - from lactate IE } \\
\text { - from pyruvate IE } \\
\text { - from alanine IE }\end{array}$ & $\begin{array}{l}23.8 \pm 2.3 \\
31.7 \pm 2.6 \\
29.0 \pm 2.6 \\
38.4 \pm 2.7 \\
30.6 \pm 2.6 \\
41.1 \pm 3.0\end{array}$ & $\begin{array}{l}15.6 \pm 1.4^{\mathrm{a}} \\
22.0 \pm 2.7^{\mathrm{a}} \\
17.4 \pm 1.4^{\mathrm{a}} \\
24.3 \pm 2.7^{\mathrm{a}} \\
17.9 \pm 1.4^{\mathrm{a}} \\
25.0 \pm 2.8^{\mathrm{a}}\end{array}$ \\
\hline $\begin{array}{l}\text { Gluconeogenesis ( } \mu n \\
\text { - from pyruvate IE } \\
\text { - from alanine IE }\end{array}$ & $\begin{array}{l}\left.1 \cdot \min ^{-1}\right) \\
4.88 \pm 0.31 \\
5.12 \pm 0.38\end{array}$ & $\begin{array}{l}3.75 \pm 0.40^{\mathrm{a}} \\
3.79 \pm 0.45^{\mathrm{a}}\end{array}$ \\
\hline
\end{tabular}

Results are shown as mean \pm SEM. ${ }^{\mathrm{a}} p<0.05,{ }^{\mathrm{b}} p<0.01$ vs controls. Gluconeogenesis expressed as \% of EGP is shown as uncorrected (upper line) and corrected (lower line). Absolute gluconeogenesis is shown only as corrected value

Table 4 and the corresponding metabolic fluxes, expressed relative to CS, in Table 5. Compared to control subjects, diabetic patients had a non-significant decrease in rates V8 and V9 (phosphoenolpyruvate to glucose). Other rates were nearly identical in the two groups; the PC over PDH activity ratios were not different. The intra-hepatic dilution factor $\mathrm{F}$ was also comparable $(1.34 \pm 0.02$ in control subjects and $1.39 \pm 0.05$ in diabetic patients). These dilution factors were also calculated from the labelling pattern of glucose shown in Table 4, according to Katz [30].
Correction factors were comparable in the two groups: (i) when PDH activity was assumed to be negligible $(1.21 \pm 0.03$ in normal subjects and $1.44 \pm 0.05$ in diabetic patients), and (ii) when PDH activity, as calculated from the labelling pattern of glutamine, was taken in account $(1.05 \pm 0.01$ and $1.02 \pm 0.05$, respectively). The corrected fractional contributions of gluconeogenesis to EGP (calculated using correction factors from the glutamine labelling pattern) are shown in Table 3; these contributions were always lower in diabetic subjects $(p<0.05)$, whatever the value used for the precursor enrichment. Comparable results, i.e. lower contribution of gluconeogenesis to EGP in diabetic subjects, were obtained when using correction factors calculated from the labelling pattern of glucose. From the corrected gluconeogenic contributions to EGP and the measured glucose production rates we calculated the absolute gluconeogenic rates. Then all the relative rates of Table 5 were converted into absolute fluxes (Table 6). The only difference between the two groups when rates are expressed as $\mu \mathrm{mol} \cdot \mathrm{kg}^{-1} \cdot \mathrm{min}^{-1}$ is the flux from PEP to glucose (i.e. twice the absolute gluconeogenic rate). But when rates are expressed as $\mu \mathrm{mol} / \mathrm{min}$, diabetic patients showed increased fluxes through PDH and PK whereas the other fluxes, including gluconeogenesis, are similar in the two groups. Each turn of Krebs cycle provides 12 ATP. Assuming than the carbon chain length of fatty acids oxidized in liver is 18 and thus that each fatty acid provides during its $\beta$-oxidation (without including the oxidation in Krebs cycle of the acetyl-CoA molecules produced) 40 ATP (5 during each turn of the $\beta$-oxidation) we calculated that ATP production through these metabolic pathways was about $19.5 \mathrm{mmol} / \mathrm{min}$ in control subjects and $25.6 \mathrm{mmol} /$ min in diabetic patients. These ATP production rates are much higher that the rate of utilization by gluconeogenesis. The rates of acetyl-CoA production from fatty acids (V2) were converted into rates of fatty acid oxidation assuming again a mean carbon chain length for fatty acids of 18 . Hepatic fatty acid oxidation was $1.60 \mu \mathrm{mol} \cdot \mathrm{kg}^{-1} \cdot \mathrm{min}^{-1}$ in control and 1.80 in diabetic patients.

Table 4. Labelling patterns of glutamate (from PAGN) and of plasma glucose

\begin{tabular}{|c|c|c|c|c|c|c|}
\hline Glutamate & K1 & $\mathrm{K} 2$ & \multicolumn{2}{|c|}{ K3 } & $\mathrm{K} 4$ & K5 \\
\hline Control subjects & $0.15 \pm 0.03$ & $0.72 \pm 0.04$ & \multicolumn{2}{|c|}{$0.59 \pm 0.03$} & $0.25 \pm 0.02$ & $0.10 \pm 0.01$ \\
\hline Diabetic patients & $0.08 \pm 0.01$ & $0.42 \pm 0.04$ & \multicolumn{2}{|c|}{$0.36 \pm 0.04$} & $0.16 \pm 0.01$ & $0.08 \pm 0.01$ \\
\hline Control subjects & $0.72 \pm 0.03$ & $0.45 \pm 0.02$ & $0.13 \pm 0.01$ & $0.14 \pm 0.02$ & $0.49 \pm 0.03$ & $0.77 \pm 0.02$ \\
\hline Diabetic patients & $0.36 \pm 0.05$ & $0.20 \pm 0.02$ & $0.07 \pm 0.01$ & $0.07 \pm 0.01$ & $0.21 \pm 0.02$ & $0.38 \pm 0.05$ \\
\hline
\end{tabular}

Results are shown as mean \pm SEM. Labelling patterns corrected for labelled $\mathrm{CO}_{2}$ re-incorporation 
Table 5. Metabolic fluxes expressed relative to citrate synthesis (CS)

\begin{tabular}{lll}
\hline & Control subjects & Diabetic patients \\
\hline V8 & $7.63 \pm 0.43$ & $6.82 \pm 1.03$ \\
V1: PDH & $2.36 \pm 0.09$ & $3.00 \pm 0.46$ \\
V6: PC-PEPCK & $27.5 \pm 3.9$ & $31.7 \pm 2.6$ \\
V2: FAox & $7.64 \pm 0.09$ & $7.01 \pm 0.42$ \\
V3: CS & 10 & 10 \\
V5: OAA->F & $100 \pm 12$ & $99 \pm 10$ \\
V4: F->OAA & $110 \pm 12$ & $109 \pm 10$ \\
V9: PEP to glucose & $5.27 \pm 0.49$ & $3.81 \pm 0.03$ \\
V7: PK & $22.3 \pm 3.6$ & $27.9 \pm 2.1$ \\
PC/PDH & $12.1 \pm 2.6$ & $11.2 \pm 1.4$ \\
F & $1.34 \pm 0.02$ & $1.39 \pm 0.09$
\end{tabular}

Results are mean \pm SEM. PDH, Pyruvate dehydrogenase; PC, pyruvate carboxylase; PEPCK, phosphoenolpyruvate carboxykinase; FAox, flux of acetyl-CoA from fatty acids; OAA $\rightarrow$ F, flux of oxaloacetate to fumarate; $\mathrm{F}->\mathrm{OAA}$, flux of fumarate to oxaloacetate; $\mathrm{PC} / \mathrm{PDH}, \mathrm{PC}$ to $\mathrm{PDH}$ activity ratio; F, dilution in oxaloacetate crossroads. These rates were calculated from the labelling patterns of glutamate shown in Table 3 according to equations of Magnusson et al. [13]

\section{Discussion}

The glucose and lactate Rt found in this report in diabetic patients agrees with previous reports. Lactate $\mathrm{Rt}$ was elevated in diabetic patients as found previously [3, 31]. Glucose Rt, expressed relative to body weight, was only moderately increased in mildly hyperglycaemic diabetic subjects [4-6] when appropriate priming was performed. However, we found that EGP was largely increased in the diabetic group when expressed per minute; this means that, unless there was a large (i.e. 1.6 times) increase in the mass of glucose producing tissue, glucose production per unit of glucose producing tissue is increased in diabetic subjects.

Our main objective was to quantitate gluconeogenesis in normal and NIDDM post-absorptive subjects. Using the labelling patterns of plasma glucose and of the glutamine moiety of PAGN and three calculations we found that gluconeogenesis accounted for about $40 \%$ of EGP in post-absorptive control subjects. Neither this relative nor the absolute contri- bution of gluconeogenesis to EGP was increased in NIDDM patients. They were decreased or normal, depending on whether they are expressed per minute or relative to body weight. The intrahepatic dilution factors (F) obtained in this report are consistent with previous studies whether also using phenylacetate to sample liver glutamine [13, 14, 26] or measuring directly by using the labelling pattern of liver glutamate $[9,16]$. F was found to be around 1 in post-absorptive monkeys [26]; it was $1-1.2$ in fasted rats, $1.2-1.4$ in fed rats $[9,16], 1.1-1.2$ in $24 \mathrm{~h}$ fasted normal humans and around 1 in normal post-absorptive subjects fed with i.v. glucose $[13,14]$. Isotopic dilution in the Krebs cycle has also been calculated with other methods. Tayek and Katz [10] found slightly higher values (1.5) in post-absorptive normal humans. However, they used a uniformly labelled tracer and the calculation of the dilution includes, contrary to studies with $\left[3-{ }^{13} \mathrm{C}\right]$ lactate, the loss of label in carbon 1 of pyruvate, as labelled $\mathrm{CO}_{2}$, after equilibration of oxalo-acetate with fumarate-malate. Therefore, it is not surprising that they found a higher intra-hepatic dilution factor. Other authors used the labelling pattern of plasma glucose and equations developed by Katz [30] to calculate this dilution in $12 \mathrm{~h}$ fasted infants [29] and in normal adults [3] infused with [3$\left.{ }^{13} \mathrm{C}\right]$ or $\left[3-{ }^{14} \mathrm{C}\right]$ lactate. They reported correction factors of 1.08-1.24 and of $1.39 \pm 0.06$, respectively. However, they did not correct glucose labelling for labelled $\mathrm{CO}_{2}$ incorporation in carbons 3 and 4, and assumed in their calculations that PDH activity was negligible, which is questionable. Finally, it seems, at least in one study [29], that they used for their calculation the ratio of $\mathrm{C} 1+\mathrm{C} 2$ over $\mathrm{C} 3$ enrichment (of $\mathrm{C} 5+\mathrm{C} 6$ over $\mathrm{C} 4$ ) instead of the average enrichment of $\mathrm{C} 1$ and $\mathrm{C} 2$ over $\mathrm{C} 3$ enrichment. These points make the interpretation of their data difficult.

We used peripheral pyruvate or alanine enrichment to solve the problem of the dilution of the gluconeogenic precursor IE between peripheral circulation and liver. We previously found in rats that peripheral plasma pyruvate IE, although higher than liver pyruvate enrichment, was a better approximation of this enrichment than peripheral lactate IE

Table 6. Absolute values of metabolic fluxes

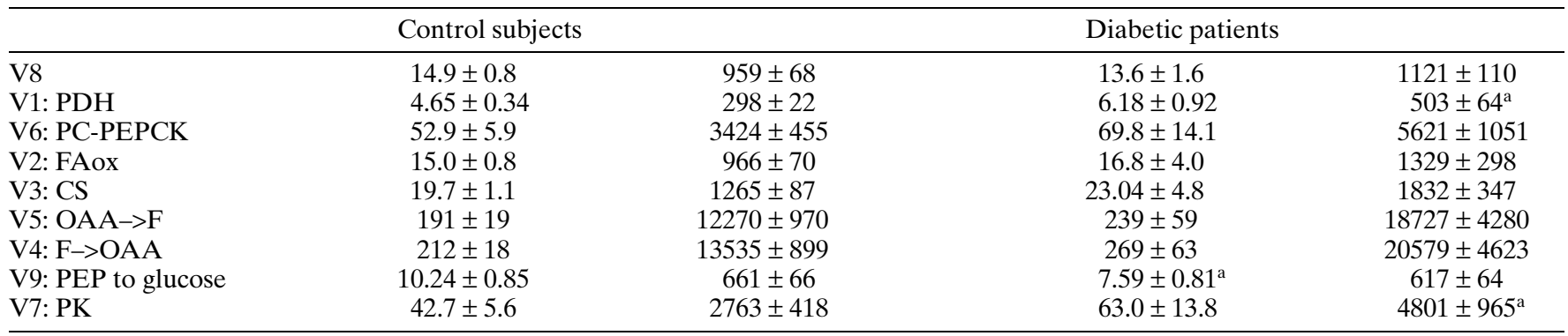

Values $\left(\mu \mathrm{mol} \cdot \mathrm{kg}^{-1} \cdot \mathrm{min}^{-1}\right.$ and $\mu \mathrm{mol} / \mathrm{min}$, first and second column for control and diabetic subjects) are shown as mean $\pm \mathrm{SEM}$. Gluconeogenesis was calculated using plasma alanine enrichment. ${ }^{a} p<0.05$ vs control subjects 
[12]. Moreover we had evidence that this isotopic disequilibrium between plasma and liver pyruvate is less important in bigger animal species and in humans [12]. The use of plasma alanine IE is based on the fact that pyruvate-alanine interconversion occurs in tissues; therefore, plasma alanine could be representative of tissue pyruvate enrichment during infusion of labelled lactate or pyruvate. We could not measure alanine IE during previous experiments in rats in vivo $[9,12]$ but we found that alanine IE in the effluent of isolated rat livers perfused with $\left[3-{ }^{13} \mathrm{C}\right]$ lactate was comparable to that of liver pyruvate [16]. Moreover, Jahoor et al. [18] found during the infusion of [U$\left.{ }^{13} \mathrm{C}\right]$ glucose in infant pigs, a comparable IE of plasma and apoprotein B100 alanine showing that plasma alanine was representative of hepatic alanine enrichment. We found that plasma pyruvate and alanine IE were comparable when lactate was the tracer infused. We propose therefore that one or the other could be used in humans, to estimate intra-hepatic pyruvate enrichment.

Previous estimates of gluconeogenesis in normal post-absorptive subjects ranged from 20 to $70 \%$. Our results are higher than those $(30 \%)$ reported using the splanchnic balance technique by Wahren et al. [32]. However, this method does not take in account the contribution of gluconeogenic precursors released by the gut. Pimenta et al. [33] found using ${ }^{14} \mathrm{C}$ lactate that gluconeogenesis from lactate accounted for a minimum of $18.6 \pm 2.4 \%$ of EGP; this uncorrected value for gluconeogenesis agrees well with the one $(23 \%)$ we found. Landau et al. [34], using deuterated water, and Petersen et al. [35], using nuclear magnetic resonance measurement of hepatic glycogen content reported higher gluconeogenic values of $47 \pm 2 \%$ and $55 \pm 6 \%$, respectively. Gluconeogenesis from glycerol is not included in our measurements which could partly explain these differences. The nuclear magnetic resonance method measures only net glycogen mobilization. There is evidence that glycogen synthesis and degradation occur simultaneously [36, 37]; therefore one cannot exclude the possibility that nuclear magnetic resonance measurements underestimated the true glycogenolytic rate and thus overestimated the contribution of gluconeogenesis to EGP. Gay et al. [38] also found higher fractional gluconeogenesis $(50 \%)$. However, the method used, combining indirect calorimetry and labelling before the measurements of glycogen by ingested ${ }^{13} \mathrm{C}$ enriched carbohydrate, relies on several assumptions which need validation, especially that there is no significant muscle glycogenolysis contributing ${ }^{13} \mathrm{C}$-labelled precursors to oxidation and gluconeogenesis.

Whatever the labelling pattern (glucose or glutamine of PAGN) used for the calculation we found that neither the relative nor the absolute gluconeogenic rates were increased in the diabetic patients studied. There are few studies measuring gluconeogenesis in human diabetes. Elevated gluconeogenic rates have been reported in insulin-dependent diabetes [14] but the increase was moderate. Yki-Jarvinen et al. [31], using [U- $\left.{ }^{14} \mathrm{C}\right]$ lactate, reported in NIDDM an uncorrected contribution of lactate to EGP of $12 \pm 1 \%$, comparable to our results. Tayek et al. [10] found no increase in NIDDM patients of the fractional contribution of gluconeogenesis to EGP. Of the two reports by Consoli et al. [2, 3] of increased gluconeogenesis in NIDDM patients the first used, as discussed previously, a method not adapted to in vivo studies; the interpretation of the second is made difficult by the absence of correction of the labelling pattern of glucose for incorporation of labelled $\mathrm{CO}_{2}$. Using nuclear magnetic resonance for measuring net hepatic glycogenolysis Magnusson et al. [39] found a moderate increase of gluconeogenesis in NIDDM patients but the fasting was prolonged for $23 \mathrm{~h}$. Lastly, Perriello et al. [40] reported that gluconeogenesis from alanine was increased in NIDDM subjects, even with mild hyperglycaemia. The tracer used ([U${ }^{14} \mathrm{C}$ ]alanine) and the timing of the infusions were different and there was no attempt to correct for the pre- and intra-hepatic dilutions. However, the reasons for the discrepancy between Perriello's report and the present one are unclear. There is evidence that kidneys significantly contribute to gluconeogenesis in normal subjects and that this contribution could be higher during diabetes, as least in IDDM patients [41]. Human kidneys also conjugate phenylacetate with glutamine but, since they lack glutamine synthase [42], this does not allow their intermediary metabolism to be assessed. We may therefore have underestimated gluconeogenesis somewhat in the subjects we investigated, this possibly being more important in diabetic patients.

We calculated other intrahepatic metabolic fluxes in control and diabetic subjects. V8 (lactate-pyruvate utilization) was lower than the apparent lactate Rt in NIDDM patients but higher in control subjects, a clear impossibility. However, we used the venous-arterial mode for measuring lactate Rt which results in some underestimation of lactate Rt [12]. Moreover, the production of lactate by the gut is not taken in account by these measurements. We found no modification in NIDDM of the PC/PDH activity ratio. Hepatic fatty acid oxidation rates in control and NIDDM were also comparable: the absolute fatty acid oxidation rates, when expressed as $\mu \mathrm{mol} \cdot \mathrm{kg}^{-1} \cdot \mathrm{min}^{-1}$, were about 1.6 in control and 1.8 in diabetic subjects. Moreover, D- $\beta$-hydroxybutyrate levels were lower in NIDDM than in control subjects despite comparable NEFA concentrations. Therefore, we have no evidence of an increased hepatic fatty acid oxidation which has been proposed to stimulate gluconeogenesis in NIDDM. Assuming a total NEFA flux of $6-7 \mu \mathrm{mol} \cdot \mathrm{kg}^{-1} \cdot \mathrm{min}^{-1}$ and an utilization by liver of 
$25-30 \%$ of total NEFA flux [43], oxidation would account for more than $80 \%$ of the metabolic fate of fatty acids taken up by the liver and for $25 \%$ of whole body NEFA utilization. The estimates of total ATP production agree with values derived from measurement of oxygen consumption [44]. These results support the validity of the approach we used to obtain important insights into liver metabolism.

In conclusion we found no increase of either fractional or absolute gluconeogenesis in NIDDM patients despite moderate increases in glucose Rt and apparent lactate Rt. We found also no significant modifications of intra-hepatic metabolic fluxes, in particular no increase in liver fatty acids oxidation or in the $\mathrm{PC} / \mathrm{PDH}$ activity ratio.

Acknowledgements. This work was supported by grants from the Association Francaise des Diabétiques, the Fondation de France and the North Atlantic Treaty Organization. We wish to thank the nurses of the Centre de Recherche en Nutrition Humaine for their help when performing the tests and all the subjects who volunteered for this study.

\section{References}

1. De Fronzo RA (1988) The triumvirate: $\beta$-cells, muscles, liver. A collusion responsible for NIDDM. Diabetes 37: 667687

2. Consoli A, Nurjhan N, Capani F, Gerich JE (1989) Predominant role of gluconeogenesis in increased hepatic glucose production in NIDDM. Diabetes 38: 550-557

3. Consoli A, Nurjhan N, Reilly J, Bier D, Gerich JE (1990) Mechanism of increased gluconeogenesis in NIDDM. J Clin Invest 86: 2038-2045

4. Hother-Nielsen O, Beck-Nielsen H (1990) On the determination of basal glucose production rates in patients with NIDDM using primed-continuous $\left[3-{ }^{3} \mathrm{H}\right]$ glucose infusion. Diabetologia 33: 603-610

5. Jeng CY, Sheu WHH, Fuh MMT, Chen YDI, Reaven GM (1994) Relationship between hepatic glucose production and fasting plasma glucose concentration in patients with NIDDM. Diabetes 43: 1440-1444

6. Rigalleau V, Beylot M, Laville M et al. (1996) Measurement of post-absorptive glucose kinetics in non-insulin-dependent diabetic patients: methodological aspects. Eur J Clin Invest 26: 231-236

7. Schumann WC, Magnusson I, Chandramouli V, Kumaran K, Wahren J, Landau BR (1991) Metabolism of $\left[2-{ }^{14} \mathrm{C}\right]$ acetate and its use in assessing hepatic Krebs cycle activity and gluconeogenesis. J Biol Chem 266: 6985-6990

8. Consoli A, Nurjhan N, Capani F, Pangburn JT, Lapena D, Gerich JE (1993) Limitations in the use of $\left[2-{ }^{13} \mathrm{C}\right]$ acetate for measuring gluconeogenesis in vivo. Diabetes 42: 732-737

9. Beylot M, Soloviev MV, David F, Landau BR, Brunengraber H (1996) Tracing hepatic gluconeogenesis relative to citric acid cycle activity in vitro and in vivo. $\mathrm{J}$ Biol Chem 270: $1509-1514$

10. Tayek JA, Katz J (1996) Glucose production, recycling, and gluconeogenesis in normals and diabetics: a mass isotopomer [U- ${ }^{13}$ C]glucose study. Am J Physiol 270: E709-E717

11. Hetenyi G Jr (1985) Correction for the metabolic exchange of ${ }^{14} \mathrm{C}$ for ${ }^{12} \mathrm{C}$ in the pathway of gluconeogenesis in vivo. Federation Proc 41: 104-109
12. Large V, Soloviev MV, Brunengraber H, Beylot M (1995) Lactate and pyruvate isotopic enrichments in plasma and tissues of post-absorptive and starved rats. Am J Physiol 268: E880-E888

13. Magnusson I, Schumann WC, Bartsch GE et al. (1991) Non-invasive tracing of Krebs cycle metabolism in liver. J Biol Chem 266: 6975-6984

14. Landau BR, Chandramouli V, Schumann WC et al. (1995) Estimates of Krebs cycle activity and contributions of gluconeogenesis to hepatic glucose production in fasting healthy subjects and IDDM patients. Diabetologia 38: 831-838

15. James MO, Smith RL, Williams RT, Reidenberg M (1957) The conjugation of phenylacetatic acid in man, sub-human primates and some non-primate species. Proc R Soc Lond 182: 25-35

16. Large V, Brunengraber H, Odeon M, Beylot M (1997) Use of the labeling pattern of liver glutamate to calculate rates of citric acid cycle and gluconeogenesis. Am J Physiol 272: E51-E58

17. Yang D, Previs SF, Fernandez CA et al. (1996) Noninvasive probing of citric acid cycle intermediates in primate liver with PAGN. Am J Physiol 270: E882-E889

18. Jahoor F, Burrin DG, Reeds PJ, Frazer M (1994) Measurement of plasma protein synthesis rate in infant pig: an investigation of alternate tracer approaches. Am J Physiol 267: R221-R227

19. Beylot M, Riou JP, Bienvenu F, Mornex R (1983) Increased ketonaemia in hyperthyroidism; evidence for a $\beta$-adrenergic mechanism. Diabetologia 19: 505-510

20. Hales CM, Randle PJ (1963) Immunoassay of insulin with insulin antibody precipitate. Biochem J 56: 136-142

21. Harris V, Faloona GR, Unger RH (1979) Glucagon. In: Jaffe BM, HR Behrman (eds) Methods of radioimmunoassay. Academic Press, New York pp 643-671

22. Beylot M, David F, Khalfallah Y, Normand S, Large V, Brunengraber H (1994) Determination of ${ }^{13} \mathrm{C}$ urea enrichment by gas chromatography-mass spectrometry and gas chromatography isotope ratio mass spectrometry. Biol Mass Spectrom 23: 510-513

23. Tissot S, Normand S, Guilluy R et al. (1990) Use of a new gas chromatograph isotope ratio mass spectrometer to trace exogenous ${ }^{13} \mathrm{C}$ labelled glucose at a very low level of enrichment in man. Diabetologia 33: 449-456

24. Beylot M, Previs SF, David F, Brunengraber H (1993) Determination of the labeling pattern of glucose by gas chromatography-mass spectrometry. Anal Biochem 212: 526531

25. Peroni O, Large V, Beylot M (1995) Measuring gluconeogenesis with $\left[2-{ }^{13} \mathrm{C}\right]$ glycerol and mass isotopomer distribution analysis of glucose. Am J Physiol 269: E516-E523

26. Yang D, Agarwal KC, Beylot M, Soloviev MV, Brunengraber H (1993) Assay of the human liver citric acid cycle probe phenylacetylglutamine and of phenylacetate in plasma by gas chromatography-mass spectrometry. Anal Biochem 212: 277-282

27. Beylot M, David F, Brunengraber H (1993) Determination of the ${ }^{13} \mathrm{C}$ labeling pattern of glutamate by gas chromatography-mass spectrometry. Anal Biochem 212: 532-536

28. Guilluy R, Billion-Rey F, Pachiaudi C et al. (1992) On line purification and ${ }^{13} \mathrm{C}$ isotopic analysis of carbon dioxide in breath: evaluation of on-line gas chromatography-isotope ratio mass spectrometry. Anal Chim Acta 259: 193202

29. Bougneres PF, Rocchiccioli F, Nurjhan N, Zeller J (1995) Stable isotope determination of plasma lactate conversion into glucose in fasting infants. Am J Physiol 268: E652E659 
30. Katz J (1985) Determination of gluconeogenesis in vivo with ${ }^{14} \mathrm{C}$ labeled substrates. Am J Physiol 248: R391-R399

31. Yki-Jarvinen H, Helve E, Sane T, Nurjhan N, Taskinen MR (1989) Insulin inhibition of overnight glucose production and gluconeogenesis from lactate. Am J Physiol. 256: E732-E 739

32. Wahren J, Felig P, Cerasi E, Luft R (1972) Splanchnic and peripheral glucose and amino acid metabolism in diabetes mellitus. J Clin Invest 51: 1870-1872

33. Pimenta W, Nurjhan N, Jansson PA, Stumvoll M, Gerich JE, Korytkowski M (1994) Glycogen: its mode of formation and contribution to hepatic glucose output in postabsorptive humans. Diabetologia 37: 697-702

34. Landau BR, Wahren J, Chandramouli V, Schumann WC, Ekberg K, Kalhan SC (1996) Contributions of gluconeogenesis to glucose production in the fasted state. J Clin Invest 98: 378-385

35. Petersen KF, Price T, Cline GW, Rothman DG, Shulman GI (1996) Contribution of net hepatic glycogenolysis to glucose production during the early postprandial period. Am J Physiol 270: E186-E191

36. Magnusson I, Rothman DL, Jucker B, Cline GW, Shulman RG, Shulman GI (1994) Liver glycogen turnover in fed and fasted humans. Am J Physiol 266: E796-E803

37. Roden R, Perseghin G, Petersen KF et al. (1996) The roles of insulin and glucagon in the regulation of hepatic glyco- gen synthesis and turnover in humans. J Clin Invest 97: 642-648

38. Gay LJ, Schneiter PH, Schutz Y, Di Vetta V, Jéquier E, Tappy L (1994) A non-invasive assessment of hepatic glycogen kinetics and post-absorptive gluconeogenesis in man. Diabetologia 37: 517-523

39. Magnusson I, Rothman DL, Katz LD, Shulman RG, Shulman GI (1992) Increased role of gluconeogenesis in type II diabetes mellitus. J Clin Invest 90: 1323-1327

40. Periello G, Pampanelli S, Del Sindaco P et al. (1996) Evidence of increased systemic glucose production and gluconeogenesis in an early stage of NIDDM. Diabetes 46: 1010-1016

41. Stumvoll M, Meyer C, Mitrakou A, Nadkarni V, Gerich JE (1997) Renal glucose production and utilization: new aspects in humans. Diabetologia 40: 749-757

42. Lemieux G, Baverel G, Vinay P, Wadoux P (1976) Glutamine synthetase and glutamyltransferase in the kidney of man, dog and rat. Am J Physiol 231: 1068-1073

43. Wahren J, Hagenfeldt L, Felig P (1975) Splanchnic and leg exchange of glucose, amino acids and free fatty acids during exercise in diabetes mellitus. J Clin Invest 55: 1303 1309

44. Newsholme EA, Leech AR (1983) Biochemistry for the medical sciences. John Wiley and Sons, New York, p 952 